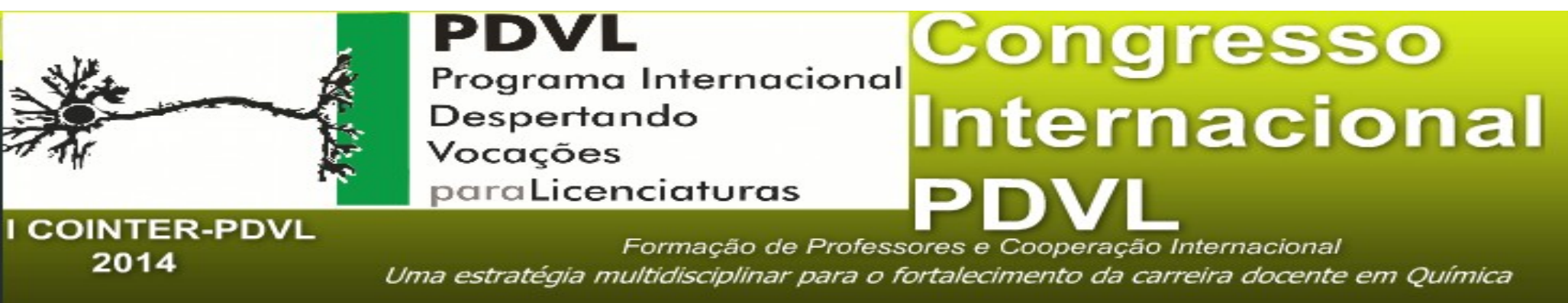

\title{
O “SER PROFESSOR” DOS ESTUDANTES CONCLUINTES DOS CURSOS DE LICENCIATURA EM GEOGRAFIA E LICENCIATURA EM QUÍMICA DO IFPE.
}

\author{
Bruno Vinícius de Oliveira Neves \\ José Henrique Duarte Neto.
}

\section{RESUMO}

Este Plano de Atividades. Esta temática de pesquisa insere-se no Projeto de Pesquisa A Organização do Trabalho Educativo e suas Implicações na Formação do Ser Social, cujo objeto de estudo consiste na relação entre o trabalho educativo desenvolvido no espaço escolar, em todos os níveis, e as suas implicações na formação do educando. Incumbese essa pesquisa em buscar compreender a concepção de "ser professor", formulada pelos estudantes concluintes dos cursos de licenciatura em Geografia e licenciatura em Química do Instituto Federal de Educação, Ciência e Tecnologia de Pernambuco. O referencial teórico metodológico baseia-se na crítica às pedagogias da racionalidade técnica e no ideário da epistemologia da prática. A argumentação metodológica referencia-se em uma abordagem de pesquisa que busca perceber o processo investigatório como totalidade. Optamos por uma abordagem dialética, por compreender que para dar conta da complexidade da realidade com suas múltiplas dimensões, precisamos utilizar um método que tenha as suas categorias de análises extraídas da própria realidade, apreendendo e interpretando as suas relações, o seu movimento e as mudanças inerentes à sua natureza. Como procedimento de construção do conhecimento novo, nos apoiamos na análise de conteúdo.

Palavras-chave: Ser social, Formação de professores, epistemologia da prática.

\section{INTRODUÇÃO}

Os processos de formação situam-se historicamente. Na qualidade de prática social, os processos formativos estão mediados pelas relações que os homens estabelecem entre si, para garantir a produção e a reprodução de sua existência. A educação como fenômeno intrínseco à existência humana tem se apresentado, nas sociedades contemporâneas, como condição necessária à socialização dos sujeitos, bem como 
indispensável e reprodução do gênero humano, com base na compreensão de que o homem, como sujeito criador de cultura, lega às gerações futuras, todo um patrimônio material/imaterial, constituído com base nas atividades educativas e formadoras, de caráter sistemática e intencional, desenvolvida no âmbito da escola. Esta instituição, ao longo do desenvolvimento da humanidade, angariou para a si, a condição de ser o espaço por excelência, aonde se trabalha com o conhecimento sistematizado.

A condição histórica da escola remete a sua função social, para o atendimento às necessidades sociais de seu tempo. Independentemente do nível de escolarização ou da modalidade do ensino, a educação em qualquer momento histórico, busca responder aos anseios do homem em particular e da sociedade em geral. Na sociedade contemporânea, em que se percebe uma acentuada presença de contradições e conflitos sociais, os processos educativos são eles também, produzidos nestas condições. A escola reflete, em sua estrutura e funcionamento, as contradições sociais. No que tange à formação de professores, as pesquisas produzidas ao longo do tempo (GATTI, 2009) (DUARTE NETO, 2013), têm trazido essa realidade. Ao que tudo indica o impasse da formação de professores, parece coincidir com o da condição humana em geral, neste momento histórico. É possível perceber nessa dimensão da existência, uma contradição insolúvel, nos marcos da sociedade atual, entre a formação necessária, destinada a atender às demandas de universalidade do ser social e aquelas definidas como prioritárias ao atendimento das finalidades imediatas e parciais. Devido a essa contradição, provavelmente insolúvel nos marcos dessa estrutura societal, tem impedido ser desencadeado um processo de formação integral. Em decorrência, tem sido apresentado como causa desse impedimento problemas que existem no seio dos próprios mecanismos de formação, que tem o ato educativo como mediação para a conquista desse tipo de sujeito. Apontam-se problemas nos métodos; nos conteúdos; na formação dos profissionais da educação, no funcionamento das instituições escolares, e etc. Esses fatores não devem ser desconsiderados, mas também é um equívoco tomá-los em si mesmo, deslocados das condições históricas. O fato é que, na atual realidade, como o trabalho está dirigido à produção de valor de troca, portanto orientado para a formação de um sujeito-em-si, a formação está parcializada. Reiteramos que o caráter de universalidade da formação, de natureza integral, está alienado e, portanto, subordinado aos ditames da formação para o mercado, onde a utilidade se torna o elemento fundamental de toda a atividade humana, onde o ser social se insere e se constrói. 
Assim, nos interessa investigar, com base nos processos formativos ocorridos nos cursos de formação de professores do Instituto Federal de Educação, Ciência e Tecnologia de Pernambuco (IFPE), qual a concepção de “ser professor” que o estudante concluinte formulou, em decorrência de seu processo de formação. Deste modo, elaboramos algumas questões que julgamos importante, como norteadoras de nossas formulações teóricas e de orientação à construção das estratégias de coleta de informações. Questões, como: Que compreensão os professores têm do seu papel social? Ensinar para quê e para quem? Que níveis de compreensão têm da realidade em suas diferentes dimensões? Que compreensão tem o professor de si mesmo como aprendiz e ensinante? Que ideologias estão subjacentes à formação e a prática do professor? Que anseios, que expectativas e preocupações imediatas e particulares têm os professores com relação a sua prática - (profissão)? Que transformação os estudantes do curso de licenciatura (geografia e química) sofrem quando saem do IFPE para atuar como professores? Que características (perfil) tem o aluno (futuro professor) ao sair do IFPE? Estas e outras questões, que ao longo do processo investigativo podem surgir, poderão para ajudar a identificar as causas da crise que tem se abatido sobre a profissão docente, e a partir do conhecimento novo produzido, contribuir no avanço da superação das questões aqui anunciadas.

\section{Concepções e Práticas de Formação de Professores}

Assim como milhares de professores no Brasil, a nossa formação docente, realizada no âmbito das universidades públicas brasileiras, foi marcada por uma forte presença do modelo tecnicista de ensino. Grosso modo, o que orientava esta concepção era que, primeiro se aprendia a fazer para depois, dependendo das qualidades individuais, da capacidade para memorizar técnicas de ensino, das “destrezas” de cada um, da vocação, e até do amor à profissão, a “prática” se realizaria conforme o receituário prescrito no momento da "teoria”, trabalhada no início do curso.

Com maior ou menor incidência destes pressupostos, a maioria dos cursos de formação de professores se assentava nestes ditames. Além disto, os cursos organizavam-se com ênfase nos conteúdos específicos ou de áreas, em detrimento dos conteúdos pedagógicos ou de formação. Assim, por exemplo, a Licenciatura em História formava muito mais o historiador, do que o professor de História, que quando ao concluir o curso, com ou sem a experiência de docente, acreditava que saber História era suficiente para ser professor desta disciplina, negligenciava-se os conteúdos de 
formação pedagógica. E isto acontecia com as demais licenciaturas, nas mais diferentes áreas do conhecimento.

Atualmente, as instituições que formam professores, dentro dos seus limites, têm procurado repensar a formação que tem sido oferecida, apesar das dificuldades e das particularidades de cada espaço onde a formação se dá. O debate tem sido profícuo, pois vem possibilitando revisões em antigas práticas que insistem em manter distância entre o professor que se forma e a realidade que o espera. A estrutura curricular dos cursos de formação de professores, algumas vezes marcada por enormes lacunas teóricas e conceituais, tem encontrado dificuldades para articular teoria e prática de forma a torná-las uma unidade dialética. A desarticulação entre as disciplinas de formação específica e as de natureza didática, não raras vezes, cria obstáculos para que o aluno perceba as relações internas entre os conhecimentos essências à sua formação e aqueles que deverá utilizar no exercício da atividade docente, contribuindo para o distanciamento entre o que se “ensina” no espaço de formação e as escolas onde os professores atuam ou estão prestes a atuar.

Quando nos debruçamos em análises das propostas de formação de professores que estão presentes nas instituições formadoras, encontramos algumas variantes de formação que procurando inovar, invariavelmente, oscilam entre a tentativa de uma formação pautada na reflexão crítica e a outra baseada na racionalidade técnica. Qualquer que seja a formação, ela estará imbuída de objetivos, intencionalidades e ‘público’ que deseja alcançar. O fato é que está aí presente uma visão de mundo, de homem, de educação e de escola. Não lhe escapa a compreensão que tem da atividade docente e dos processos de aprendizagem, bem como, de qual professor precisa e para quê precisa. Esta formação, inicial e/ou continuada, também está permeada por uma concepção de currículo e de realidade escolar onde os professores da Educação Básica atuam. Apesar dos esforços dirigidos para a implementação de uma concepção de formação que atenda a uma perspectiva emancipatória, ainda estamos distantes de ver prevalecer, entre as instituições que formam professores, a concretização deste ideal. O funcionamento de cursos baseados na racionalidade técnica é uma realidade ainda bastante presente, nestas instituições.

Os estudos a respeito da racionalidade técnica, como receita ditada pelas políticas oficiais de formação de professores e por extensão como prática organizadora do processo pedagógico na escola, se aprofunda(va) na mesma intensidade em que se 
manifesta(va) a separação entre teoria e prática, entre quem pensa e realiza e entre quem manda e é mandado. O caráter autoritário da racionalidade técnica reside na impossibilidade de pensar o processo e de centrar a atenção no produto. Não se pensa a partir do sujeito e para o sujeito, a lógica deve atender ao que é previamente esquematizado e a preocupação está em alcançar resultados imediatos. O homem/sujeito não conta, é apenas parte não essencial do esquema. O fundamental é o conhecimento que este, em tese, deverá dominar para tornar-se empregável.

A partir dos anos de 1990, deu-se início a uma produção acadêmica, com a finalidade da crítica a este modelo de formação de professores. A orientação teóricoepistemológica desta crítica fez deslocar-se a atenção das técnicas de ensino, para assentar-se na "prática” do professor, ou como passou a ser conhecida a temática dos “saberes docentes”, conceito/categoria esta que passou a acompanhar-se de outras, tais como: “professor reflexivo”, “prático reflexivo”, “professor pesquisador”, “professor investigador de sua prática” e etc.. Em estudos que realizamos, (DUARTE NETO, 2010) a respeito deste ideário pedagógico, identificamos os seus pressupostos teóricos, filosóficos e pedagógicos e passamos a denominá-lo por epistemologia da prática.

\section{A Epistemologia da Prática e a Formação de Professores}

A epistemologia da prática baseia-se na compreensão de que o mundo resume-se às nossas impressões sobre ele, às nossas vivências cotidianas (DUARTE NETO, 2013). Nivela-se o mundo, reduzindo o cognoscível à experiência sensível, aos limites do empírico. Com estratégias às vezes diferentes de abordagem a respeito do trabalho e da formação docente, pautam-se todos numa crítica ao que denominam de racionalidade técnica, com especial destaque para o tipo de conhecimento e os procedimentos metodológicos que esse modelo de ensino sugere como mediador da formação. Advogam que a reflexão é um importante instrumento de desenvolvimento do pensamento e da ação e vê na reflexão sobre a prática a estratégia que pode superar a racionalidade técnica. A ênfase nessa reflexão deve-se, segundo os pensadores desse ideário, pelo fato do professor trazer em si um tipo de conhecimento que convencionaram denominar de pensamento prático. Com base nas leituras, podemos perceber que o que os autores denominam de pensamento prático do professor consiste de um cabedal de conhecimentos que o docente adquiriu a partir de sua experiência como profissional. Conhecimentos que têm origem na prática cotidiana, nas ações por ele desenvolvidas no exercício da docência e constituem, segundo os seus autores, o 
conhecimento tácito, as teorias implícitas, a respeito do como fazer. Para alguns, inclusive, esse pensamento tem início antes do exercício do magistério, começa com a sua vida escolar.

$\mathrm{Na}$ ênfase ao aspecto epistemológico não se percebe alusão a um conhecimento teórico de referência, produzido, sistematizado e elaborado pela humanidade, que o "prático reflexivo", - aqui no caso o professor -, utilize para proceder com a reflexão recomendada pela epistemologia da prática. O destaque que se dá ao conhecimento tácito e a supervalorização das teorias implícitas sugerem que sejam esses os conhecimentos mais adequados para o exercício da reflexão sobre a prática, bem como os que devem ser tomados para conteúdo da formação e da atuação profissional. É parte também do ideário a "leitura do cotidiano escolar”. Nesse sentido, a subjetividade ganha relevo. Tomam-na como sendo produto das contradições com origem no próprio sujeito, ou quando muito, da relação desse sujeito com os seus pares. Desconsidera-se, dessa forma, o plano das relações sociais e fazem-na abstrata e anistórica. A subjetividade passa a ser desenvolvida em correspondência à sua incorporação efetiva nos diversos grupos sociais a que pertence. Mas, geralmente, incorpora-se acriticamente, sem estabelecer de forma mais adequada os reais vínculos entre o grupo e as condições sócio históricas em que se situa. Essa ênfase na subjetividade faz com que mais do que o conteúdo, a importância resida no significado das coisas.

Apesar de haver outras, observamos que são quatro as categorias centrais no ideário da epistemologia da prática, sendo elas: reflexão, conhecimento, experiência e cotidiano. Esta última tem sido abordada, não raras vezes, numa relação de bastante proximidade com a categoria de "prática”, de modo que poderíamos tratá-la no sentido de “cotidiano/prática”. Referindo-se às pedagogias contemporâneas, cujos traços comuns o levaram a denominá-las de pedagogias do “aprender a aprender” Duarte (2003, 2007) tem chamado a atenção para o fato de que está presente, em sua maioria, o apelo ao conhecimento tácito, baseado no pensamento do cientista húngaro Michael Polanyi (1891 - 1976). Tomando de empréstimo esse postulado, essas pedagogias o têm como fundamental para a formação e para a prática profissional do professor -, que apesar das inúmeras denominações que recebe -, resume-se à ideia de reflexão como prática necessária do professor. Dessa forma, o conhecimento como importante mediação da formação do professor sofre demasiada influência da epistemologia do conhecimento tácito (SAIANI, 2004), constituindo-se, a nosso ver, um dos pilares 
desse ideário. No que se refere ao seu aspecto pedagógico, particularmente em relação às suas bases filosóficas, o ideário tem como núcleo do processo formativo a experiência; a prática imediata do indivíduo. O pragmatismo e a valorização excessiva da experiência do indivíduo, como centro do processo, nos indicam, que apesar da presença de várias abordagens na epistemologia da prática, as características apontadas, levam-nos a afirmar que outro importante pilar de sustentação de tal ideário é a Pedagogia da Existência. (SUCHODOLSKI, 2004). Assim, afirmamos que a epistemologia da prática se constitui, entre outros elementos, da conjunção da pedagogia da existência com os pressupostos do conhecimento tácito, e tem como objeto de interseção entre ambos, a experiência do indivíduo. Esta experiência, tomada em seus pressupostos, é o “cotidiano/prática” sobre a qual a ação se realiza e produz as bases para a construção do conhecimento, que é mediador na formação do professor.

A partir de nossa perspectiva teórico-metodológica, esboçamos a compreensão de formação de professores com base na crítica aos ideários pedagógicos tratados acima. Somos do entendimento de que a educação como práxis social pressupõe a existência humana. É inconcebível a ideia de educação, anterior ao ser social (DUARTE NETO, 2013). Tomar a educação numa perspectiva do materialismo histórico e dialético é considerá-la na estreita relação com o trabalho, como categoria fundante e explicativa da constituição e desenvolvimento do ser social. Compreender o trabalho como atividade criadora do homem requer concebê-la no sentido geral, enquanto dimensão ontológica e em sua condição histórica, ou seja, sujeita às determinações advindas das relações sociais, construídas pelos homens, a partir das suas condições reais de existência. O esforço consiste então em realizar uma abordagem que contemple os aspectos ontológicos e históricos dos nexos em questão. Trata-se então da tríade: ser social, trabalho e educação. Nesse sentido, tomamos como perspectiva de abordagem teórica a categoria de trabalho educativo, elaborada por Dermeval Saviani (2005), que a define como sendo:

$\mathrm{O}$ ato de produzir, direta e intencionalmente, em cada indivíduo singular, a humanidade que é produzida histórica e coletivamente pelo conjunto dos homens. Assim, o objeto da educação diz respeito, de um lado, à identificação dos elementos culturais que precisam ser assimilados pelos indivíduos da espécie humana para que eles se tornem humanos e, de outro lado e concomitantemente, à descoberta das formas mais adequadas de atingir esse objetivo (p. 13). 
Observa-se que a formulação dessa categoria, pressupõe uma concepção de formação humana, baseada em uma teoria e um método de abordagem do ser social. Com relação à teoria, está baseada nos pressupostos do materialismo histórico e o método é o dialético, entendido na perspectiva da dialética marxista. É nessa relação que se situa o ser social sobre e com o qual se desenvolve um conjunto de atividades pedagógicas, cuja finalidade é atender as exigências ontológicas e históricas de produção e reprodução da existência do gênero humano. Do ponto de vista das práticas educativas, a categoria expressa a necessária unidade entre conteúdo e forma, nos processos de formação. Ou seja, diz respeito por um lado aos conhecimentos que deverão mediar a formação e por outro, refere-se à escolha do modo mais adequado para favorecer a aquisição, destes conhecimentos, por parte do educando. Entretanto, essa relação não está circunscrita ao âmbito do espaço escolar, ou mesmo, no plano da ação meramente pedagógica. Essa relação situa-se no tempo e no espaço, ou seja, reflete as condições sócio históricas a partir das quais os homens se organizam para produzir e reproduzir a sua existência.

\section{METODOLOGIA}

O nosso referencial teórico-metodológico requer abordar o problema de pesquisa considerando as relações sócias históricas, que favorecem os processos de produção e reprodução da existência do ser social. Desse modo, é importante um referencial teórico-metodológico que perceba o processo de pesquisa como totalidade, que requeira tomar os seus diversos aspectos em estreita relação de dependência e de determinações recíprocas. Optamos por uma abordagem dialética, por compreender que para dar conta da complexidade da realidade com suas múltiplas dimensões, precisamos utilizar um método que tenha as suas categorias de análises extraídas da própria realidade, apreendendo e interpretando as suas relações, o seu movimento e as mudanças inerentes à sua natureza (LEFEBVRE, 1979) para que a ela retorne, em um processo de construção e reconstrução do objeto de estudo. Um método que permita ordenar, disciplinar e sistematizar o processo de trabalho, sendo capaz de conceber esta realidade em sua totalidade, mas que também não ignore, por outro lado, aspectos que lhes são singulares, particulares e que favoreça relações entre aspectos de natureza específica e geral, entre objetividade e subjetividade (FRIGOTO, 2000).

Com relação aos elementos procedimentais de pesquisa, definimos como campo O Instituto Federal de Educação, Ciência e Tecnologia de Pernambuco (IFPE), 
especificamente o Curso de Licenciatura em Geografia - Campus Recife e o Curso de Licenciatura em Química - Campus Vitória de Santo Antão. Os sujeitos da pesquisa constituem-se dos estudantes concluintes destes cursos, que tenham vivenciado ao menos $75 \%$ da integralização do matriz curricular. No que tange ao processo de coleta de informações esta ocorrerá a partir da elaboração e aplicação de instrumentos, tais como: questionários, entrevistas e a realização de grupos focais. Podendo ser utilizado outros instrumentos, na medida em que o processo de investigação sugerir.

O procedimento para o tratamento e análise dos dados, far-se-á com base na análise de conteúdo. No interior da análise de conteúdo, usaremos o procedimento da análise temática, levando em consideração os “pólos cronológicos” de que nos fala Bardin (1977): 1) a pré-análise; 2) a exploração do material; 3) o tratamento dos resultados. O trabalho coletivo, com base em reuniões sistemáticas de estudos, partir das leituras sistemáticas e orientadas da bibliografia definida, favorecerá a discussão teórica e conceitual e propiciará a socialização dos conhecimentos a serem construídos. Os encontros semanais ocorrerão com a finalidade de fazer uma exposição reflexiva das leituras realizadas, em momento oportuno, apresentar as informações coletadas, bem como proceder com o registro do conteúdo discutido, para futura elaboração de relatórios e textos (artigos) que contemplem as análises e os resultados de pesquisa.

\section{RESULTADOS ESPERADOS}

A importância deste plano de atividades reside na capacidade da crítica, que a pesquisa científica pode suscitar no sujeito envolvido no processo investigatório e a possibilidade de comprometimento, com a construção de uma educação de qualidade, em todos os níveis. O propósito reside também, na tentativa de tributar na construção de uma pedagogia, cujas práticas educativas, estejam assentadas em outras bases sociais. Consideramos eixos importantes e articuladores da formação do educador consistem da compreensão do fenômeno educativo, do papel da escola, seus determinantes sociais e condicionamentos históricos. O exercício da profissão docente exige que se tenha desenvolvido certo grau de compreensão sobre a realidade em que atua. Para garantir esta condição é importante que a formação adquirida no curso tenha como uma de suas finalidades a formulação de uma consciência crítica da sociedade, dos fundamentos teóricos e epistemológicos da educação, da percepção dos limites e possibilidades da ação pedagógica, considerando-se os dados da realidade socioeconômica e política e sua função social. Nesta perspectiva as atividades de pesquisa contribuem, de forma 
significativa, na independência intelectual do estudante, bem como na formação de valores, como a disciplina acadêmica e o comprometimento com as tarefas de construção assumidas, por ocasião do processo investigatório desenvolvido.

\section{Referências Bibliográficas}

BARDIN, Laurence. Análise de Conteúdo. Tradução de Luís Antero Reto e Augusto Pinheiro. Lisboa: Edições 70, 1977.

DUARTE, Newton. Conhecimento Tácito e Conhecimento Escolar na Formação do Professor (Porque Donald Schön não entendeu Luria). Educação e Sociedade, Campinas, vol. 24, nº 83, p. 601-625, Agosto/2003.

$\begin{array}{lccccc}\text { O } & \text { Debate } & \text { Contemporâneo } & \text { das } & \text { Teorias } & \text { Pedagógicas. } \\ \text { UNESP/ARARAQUARA, } 2007 . & & & \end{array}$

DUARTE NETO, José Henrique. A práxis curricular nos cursos de formação de professores da educação básica: a epistemologia da prática e a construção do conhecimento escolar. 2010. Tese (Doutorado em Educação) Centro de Educação, Universidade Federal de Pernambuco, Recife, 2010.

A epistemologia da prática: implicações para a formação de professores da educação básica. Jundiaí-SP: Paco Editorial, 2013.

FRIGOTO, Gaudêncio. O enfoque da dialética materialista histórica na pesquisa educacional. In: FAZENDA, Ivani (Org.). Metodologia da Pesquisa Educacional. 6. ed. São Paulo: Cortez, 2000.

GATTI, Bernadete. Atratividade da Carreira Docente no Brasil. Fundação Carlos Chagas. São Paulo, 2009.

LEFEBVRE, Henri. O Marxismo. 5. ed. São Paulo: Difel, 1979.

SAIANI, Cláudio. O Valor do Conhecimento Tácito: A epistemologia de Michael Polanyi na escola. São Paulo: Escrituras, 2004.

SAVIANI, Dermeval. Pedagogia Histórico-Crítica. 9. ed. Campinas, SP: Autores Associados, 2005Dermeval Saviani (2005)

SUCHODOLSKI, Bogdan. A Pedagogia e as Grandes Correntes Filosóficas: a pedagogia da essência e a pedagogia da existência. 2. ed. São Paulo: Centauro, 2004 